\title{
PENGARUH KUALITAS PRODUK, PROMOSI, DAN DESAIN TERHADAP PEMBELIAN SEPEDA MOTOR YAMAHA N-MAX PADA CV. WAJA MOTOR CABANG UBUD GIANYAR
}

\author{
Pande Luh Gede Vera Purnama Dewi ${ }^{1}$ \\ I Made Santosa ${ }^{2}$
}

Fakultas Ekonomi Universitas Ngurah Rai

\begin{abstract}
ABSTRAK
Tujuan penelitian ini untuk mengetahui pengaruh kualitas produk, promosi, dan desain secara parsial dan pengaruh kualitas produk, promosi, dan desain secara simultan di CV. Waja Motor Cabang Ubud Gianyar dengan 95 responden dalam penelitian ini. Pengumpulan data dengan menyebarkan kuesioner. Berdasarkan analisis, maka diperoleh kesimpulan bahwa 1) Dari hasil analisis regresi linier berganda diperoleh persamaan regresi $\mathrm{Y}=5,519+0,359 \mathrm{X} 1,0,338 \mathrm{X} 2,0,300 \mathrm{X} 3$. Ini menunjukkan adanya pengaruh positif dan signifikan antara kualitas produk, promosi, dan desain terhadap keputusan pembelian. 2) Dari hasil analisi determinasi (R2) sebesar $25,7 \%$ berarti kualitas produk, promosi, dan desain berpengaruh terhadap keputusan pembelian sebesar 25,7\%. 3) Berdasarkan hasil T-test diperoleh bahwa promosi mempunyai pengaruh yang lebih kuat dibandingkan dengan kualitas produk dan desain, ditunjukkan oleh nilai t-hitung terbesar dibandingkan variabel lainnya yaitu sebesar, 3,475 dengan signifikan 0,001. 4) Dari hasil analisis F-test diperoleh bahwa sig. F adalah 0,000 lebih kecil dari 0,05 ini berarti bahwa kualitas produk, promosi, dan desain terhadap keputusan pembelian secara simultan berpengaruh signifikan.

Kata kunci : Kualitas Produk, Promosi, Desain
\end{abstract}

\begin{abstract}
The purpose of this study to determine the effect of product quality, promotion, and design partially and the effect of product quality, promotion, and design simultaneously in CV. Waja Motor Branch Ubud Gianyar with 95 respondents in this research. Data collection by distributing questionnaires. Based on the analysis, then obtained the conclusion that 1) From the results of multiple linear regression analysis obtained regression equation $Y=5,519+0,359 X 1,0,338 X 2,0,300 X 3$. This indicates a positive and significant influence between product quality, promotion, and design on purchasing decisions. 2) From result of determination analysis $(R 2)$ equal to $25,7 \%$ mean product quality, promotion, and design influence to purchasing decision equal to 25,7\%. 3) Based on T-test results obtained that the promotion has a stronger influence compared with product quality and design, indicated by the largest t-count value compared to other variables that is equal to, 3,475 with significant 0,001. 4) From the results of F-test obtained that sig. $F$ is 0.000 smaller than 0.05 this means that product quality, promotion, and design to purchase decision simultaneously have a significant effect.
\end{abstract}

Keywords: Product Quality, Promotion, Design 


\section{PENDAHULUAN}

Di dalam pembelian suatu produk, perilaku setiap pembelian seseorang dapat dikatakan sesuatu yang unik, karena preferensi dan sikap terhadap obyek setiap orang berbeda. Selain itu konsumen berasal dari beberapa segmen, sehingga apa yang diinginkan dan dibutuhkan juga berbeda. Masih terdapat banyak faktor yang berpengaruh terhadap keputusan pembelian. Produsen perlu memahami perilaku konsumen terhadap produk atau merek yang ada di pasar, selanjutnya perlu dilakukan berbagai cara untuk membuat konsumen tertarik terhadap produk yang dihasilkan. Ketatnya persaingan akan memposisikan pemasar untuk selalu mengembangkan kualitas produknya. Untuk bersaing secara efektif, sekarang banyak perusahaan menerapkan pemasaran sasaran. Perusahaan tidak memancarkan usaha pemasaran mereka, tetapi memfokuskan diri pada konsumen yang mempunyai peluang terbesar untuk mereka puaskan.

Perusahaan harus mampu mengenal apa yang menjadi kebutuhan dan harapan konsumen saat ini maupun yang akan datang. Konsumen sebagai individu dalam mendapatkan atau membeli barang telah melalui prosesproses atau tahapan-tahapan terlebih dahulu, seperti mendapat informasi baik melalui iklan atau referensi dari orang lain dan kemudian membandingkan produk satu dengan produk lain sampai akhirnya pada keputusan membeli produk itu. Perilaku konsumen tersebut merupakan fenomena yang sangat penting dalam kegiatan pemasaran perusahaan, yaitu perilaku konsumen dalam melakukan pembelian. Dan dengan hasil penelitian mengenai faktorfaktor yang mempengaruhi proses atau keputusan pembelian telah banyak dilakukan. Melalui riset ini akan dianalisis mengenai faktor-faktor yang mempengaruhi terhadap pembelian sepeda motor Yamaha N-Max. Ketertarikan pemilihan merek tersebut karena produk sepeda motor Yamaha NMax semakin diminati tidak hanya dikalangan kalangan anak muda. Gaya hidup modern merupakan salah satu faktor individu yang dapat mempengaruhi perilaku pembelian seseorang, sepeda motor Yamaha NMax adalah salah satu sepeda motor outometic atau disebut juga Skutermatik yang diminati oleh semua kalangan. Dan jika perusahaan membantu suatu konsep Marketing Mix yang baik. Agar dapat bertahan dan memenangkan persaingan CV. Waja Motor harus memahami apa yang menyebabkan pelanggan merasa puas. Promosi juga sangat berguna untuk memberikan informasi mengenai kelebihan, kegunaan produk dan dimana produk tersebut dapat diperoleh. Perlu diketahui bahwa betapa bagusnya suatu produk bila konsumen belum pernah mendengar dan merasa tidak yakin terhadap produk tersebut, maka calon konsumen tidak akan melakukan pembelian. Untuk lebih memperkenalkan produknya, CV. Waja Motor gencar melakukan kegiatan promosi untuk menarik minat beli konsumen, diantara membuat iklan melalui media cetak ataupun elektronik, menyebarkan selebaran kepada masyarakat, mengadakan pertunjukan musik, mengadakan service gratis bagi pengguna sepeda motor Yamaha, dan lain-lain.

Prestasi yang baik diraih oleh Yamaha N-Max yang mampu berada di posisi pertama padahal Yamaha N-Max ini termasuk skutermatik yang baru 
datang belakangan. Tentu saja perusahaan Yamaha tidak tinggal diam, dan untuk menjaga keamanan posisi nomer satunya. Rupanya Yamaha sadar bahwa walau pun Yamaha N-Max dibuat untuk pria, tetapiYamaha N-Max juga dapat digunakan untuk wanita. Alasan mengapa sebagian konsumen atau masyarakat cenderung lebih memilih Yamaha N-Max, karena pada saat ini sepeda motor yang diminati konsumen sebagian besar sejenis moge, dengan bodi N-Max yang hampir menyerupai moge maka banyak konsumen yang memilih N-Max. Selain itu berbagai alasan diantaranya dari segi harga $\mathrm{N}$ Max tidak terlalu mahal atau cukup terjangkau jika dilihat dari motor sejenisnya, penuh dengan teknologi baru dari Yamaha seperti BlueCore dan desain yang elegan.

Kehidupan masyarakat modern saat ini turut mempengaruhi pola perilaku masyarakat dalam pembelian. Kehidupan modern seringkali di identikkan dengan gaya hidup yang selalu mengikuti trend atau perkembangan jaman. Dalam kondisi seperti ini, keputusan memilih merek turut berperan dalam gaya hidup modern, sehingga keinginan untuk membeli produk yang bermerek turut mewarnai pola konsumsi seseorang.

Penelitian ini menganalisis faktor faktor yang mempengaruhi keputusan pembelian konsumen terhadap sepeda motor Yamaha N-Max. Beberapa penelitian menunjukkan faktor yang mempengaruhi keputusan pembelian antara lain kualitas produk, promosi, dan desain. Dari latar belakang masalah di atas, maka peneliti tertarik untuk melakukan penelitian yang berjudul "Pengaruh Kualitas Produk, Promosi dan Desain Terhadap Pembelian Sepeda
Motor Yamaha N-Max Pada CV. Waja Motor Cabang Ubud Gianyar".

\section{Rumusan Masalah}

Berdasarkan latar belakang diatas, maka rumusan masalah dalam penelitian ini adalah:

a. Bagaimanakah pengaruh kualitas produk, promosi, dan desain secara parsial terhadap pembelian sepeda motor Yamaha N-Max?

b. Bagaimanakah pengaruh kualitas produk, promosi, dan desain secara simultan terhadap pembelian sepeda motor Yamaha N-Max ?

\section{METODE PENELITIAN}

Penelitian ini dilakukan pada konsumen dengan mengambil data yang pasti pada dealer Yamaha CV.Waja Motor Cabang Ubud Gianyar yang berlokasi di Jl.Raya Ubud Gianyar. Alasan mengapa kualitas produk, promosi, dan desain menjadi objek penelitian, karena karena pada saat ini dipasaran sepeda motor Yamaha N-Max sangat diminati konsumen atau masyarakat, baik usia dewasa maupun usia lanjut dan kualitas produk, promosi, dan desain tentu sangat diperhatikan oleh setiap pembeli sepeda motor Yamaha N$\max$.

Pada penelitian ini menggunakan teknik analisis data regresi linier berganda, analisis determinasi, uji T-test dan uji F-test.

\section{HASIL DAN PEMBAHASAN}

Teknik analisis regresi linier berganda digunakan untuk mengetahui hubungan antara variabel bebas dengan variabel terikat pada penelitian ini yaitu 
pengaruh kualitas produk (X1), promosi (X2), dan desain (X3) terhadap pembelian sepeda motor Yamaha N-Max (Y) pada CV. Waja Motor Cabang Ubud
Gianyar, dapat dilihat pada tabel 1 dibawah ini.

Tabel 1. Analisis Regresi Linier Berganda

Coefficients $^{\mathbf{a}}$

\begin{tabular}{|c|c|c|c|c|c|c|}
\hline \multirow{2}{*}{\multicolumn{2}{|c|}{ Model }} & \multicolumn{2}{|c|}{$\begin{array}{l}\text { Unstandardized } \\
\text { Coefficients }\end{array}$} & \multirow{2}{*}{$\begin{array}{c}\text { Standardized } \\
\text { Coefficients }\end{array}$} & \multirow[b]{2}{*}{$\mathrm{t}$} & \multirow[b]{2}{*}{ Sig. } \\
\hline & & $\mathrm{B}$ & Std. Error & & & \\
\hline 1 & (Constant) & 5,519 & 2,584 & & 2,136 &, 035 \\
\hline & $\begin{array}{l}\text { KUALITAS_PRO } \\
\text { DUK }\end{array}$ & ,359 & , 174 & ,208 & 2,071 &, 041 \\
\hline & PROMOSI & ,338 & ,097 & ,334 & 3,475 & ,001 \\
\hline & DESAIN & ,300 & , 168 & , 169 & 1,786 & ,077 \\
\hline
\end{tabular}

a. Dependent Variable: KEPUTUSAN_PEMBELIAN

Sumber: Data diolah (2018)

Berdasarkan tebel 1. diatas hasil persamaan regresi linier dapat dijelaskan sebagai berikut :

$$
\begin{aligned}
& Y=a+\beta 1 X 1+\beta 2 X 2+\beta 3 X 3 \\
& Y=5,519+0,359+0,338+
\end{aligned}
$$

0,300

Dari persamaan diatas dapat dijelaskan bahwa pengaruh kualitas produk $\left(\mathrm{X}_{1}\right)$, promosi $\left(\mathrm{X}_{2}\right)$, desain (X3), keputusan pembelian (Y) yaitu sebagai berikut:

Nilai $\mathrm{a}=5,519$ yang artinya bahwa jika kualitas produk, promosi dan desain tidak ada atau bernilai nol, maka keputusan pembelian sepeda motor $\mathrm{N}$-max sebesar 5,519.

Nilai $\beta 1=0,359$, dengan asumsi bahwa jika variabel lainnya bernilai tetap, maka apabila kualitas produk mengalami kenaikan, keputusan pembelian akan mengalami peningkatan, dan sebaliknya apabila kualitas produk mengalami penurunan maka kepuasan konsumen juga mengalami penurunan.

Nilai $\beta 2=0,338$, dengan asumsi bahwa variabel bebas lainnya bernilai tetap, maka variabel harga mengalami kenaikan, keputusan pemnbelian sepeda motor N-max juga akan mengalami peningkatan, dan sebaliknya apabila variabel harga mwngalami penurunan maka keputusan pembelian sepeda motor N-max juga mengalami penurunan.

Nilai $\beta 3=0,300$, dengan asumsi apabila variabel bebas lainnya bernilai tetap, maka jika variabel desain mengalami kenaikan, keputusan pembelian sepeda motor N-max juga mengalami peningkatan, dan sebaliknya apabila variabel desain mengalami penurunan maka 
keputusan pembelian sepeda motor $\mathrm{N}$-max juga mengalami penurunan.

Dengan pernyataan diatas berarti apabila variabel kualitas produk, promosi, dan desain meningkat, maka akan meningkat pula keputusan pembelian pada CV. Waja Motor Cabang Ubud Gianyar.

\section{Analisis Determinasi}

Koefisien Determinasi (R2) merupakan koefisien yang digunakan untuk mengukur seberapa jauh kemampuan model dalam menerangkan variasi variabel independen. Variabel bebas kualitas produk (X1), promosi (X2), dan desain (X3) terhadap keputusan pembelian (Y) variabel terikat pada CV. Waja Motor Cabang Ubud Gianyar, dapat dilihat pada tabel 2:

Tabel 2. Tabel Analisis Koefisien Determinasi

\begin{tabular}{|c|c|c|c|c|}
\hline \multicolumn{5}{|c|}{ Model Summary } \\
\hline Model & $\mathrm{R}$ & R Square & $\begin{array}{l}\text { Adjusted R } \\
\text { Square }\end{array}$ & $\begin{array}{l}\text { Std. Error of the } \\
\text { Estimate }\end{array}$ \\
\hline 1 &, $507^{\mathrm{a}}$ & ,257 & ,233 & 2,92626 \\
\hline
\end{tabular}

Sumber: data diolah (2018)

Berdasarkan hasil perhitungan regresi dapat diketahui dari $R$ Square dengan nilai yaitu 0,257 , karena besarnya $\mathrm{R}^{2}=0,257$, maka besarnya koefisien determinasi adalah 25,7\%. Koefisien determinasi $25,7 \%$ berarti kemampuan variabel kualitas produk, promosi, dan desain dalam mempengaruhi pembelian sepeda motor $\mathrm{N}$-max pada CV. Waja Motor Cabang Ubud Gianyar adalah sebesar 25,7\%, sedangkan sisanya $74,3 \%$ dipengaruhi oleh faktor-faktor lain yang tidak dimasudkan dalam penelitian ini seperti pelayanan, spart part, harga.

Analisis Uji T ( Uji Hipotesis Secara Parsial )

Uji $t$ (test of significance individual parameter) digunakan untuk mengetahui pengaruh signifikan yang diberikan oleh variabel bebas yaitu kualitas produk, harga, dan promosi terhadap variabel terikat, yaitu kepuasan konsumen secara parsial. 
Tabel 3 Hasil Uji T

\begin{tabular}{|c|c|c|c|c|c|c|}
\hline \multicolumn{7}{|c|}{ Coefficients $^{\mathrm{a}}$} \\
\hline & & $\begin{array}{l}\text { Unsta } \\
\text { Coe }\end{array}$ & $\begin{array}{l}\text { lardized } \\
\text { cients }\end{array}$ & $\begin{array}{l}\text { Standardized } \\
\text { Coefficients }\end{array}$ & & \\
\hline \multicolumn{2}{|c|}{ Model } & $\mathrm{B}$ & Std. Error & Beta & $\mathrm{t}$ & Sig. \\
\hline \multirow[t]{4}{*}{1} & (Constant) & 5,519 & 2,584 & & 2,136 & 035 \\
\hline & $\begin{array}{l}\text { KUALITAS_PROD } \\
\text { UK }\end{array}$ &, 359 &, 174 & 208 & 2,071 & ,041 \\
\hline & PROMOSI & ,338 & 097 & ,334 & 3,475 & ,001 \\
\hline & DESAIN & ,300 & ,168 & ,169 & 1,786 & 077 \\
\hline
\end{tabular}

Sumber: data diolah (2018)

1. Pengaruh kualitas produk terhadap pembelian sepeda motor Yamaha N-Max pada CV. Waja Motor Cab. Ubud Gianyar :

Langkah-langkah pengujian hipotesis adalah sebagai berikut:

a. Perumusan hipotesis

$\mathrm{H}_{0}: \beta \mathrm{i}=0$ berarti tidak ada pengaruh yang signifikan antara kualitas produk (X1), promosi (X2) dan desain (X3) terhadap pembelian sepeda motor Yamaha N-Max (Y) pada CV. Waja Motor Cabang Ubud Gianyar.

Hi : $\beta \mathrm{i}>0$ berarti ada pengaruh yang signifikan secara parsial antara kualitas produk (X1), promosi (X2) dan desain (X3) terhadap pembelian sepeda motor Yamaha N-Max (Y) pada CV.
Waja Motor Cabang Ubud Gianyar.

Sesuai dengan hipotesis alternative ( $\mathrm{Hi}$ ) yang diajukan di atas, maka dalam pengujian ini digunakan uji sisi kanan dengan $\alpha=0,05$ dan $\mathrm{df}=\mathrm{n}-\mathrm{k}-1$.

b. Membandingkan nilai t-hitung dengan nilai t-tabel, dengan kriteria sebagai berikut :

1) Jika t-hitung $\leq \mathrm{t}$-tabel, maka $\mathrm{H}_{0}$ diterima dan Hi ditolak.

2) Jika t-hitung > t-tabel, maka $\mathrm{H}_{0}$ ditolak dan Hi diterima.

c. Perhitungan t-hitung Dari tabel di atas dapat dilihat bahwa t hitung dari variabel kualitas produk diperoleh = 2,071 > t-tabel 1,662 dengan tingkat signifikansi sebesar 0,041. Data diatas menunjukan bahwa nilai signifikan yang dihasilkan variabel kualitas produk berada dibawah 0,05 sehingga hipotesis yang menyatakan bahwa kualitas produk memberikan pengaruh yang signifikan terhadap 
pembelian sepeda motor Yamaha N-Max pada CV. Waja Motor Cab. Ubud Gianyar secara parsial dapat diterima.

d. Menggambarkan daerah penerimaan dan penolakan hipotesis. Untuk mengetahui bahwa $\mathrm{H}_{0}$ diterima atau ditolak, maka digambarkan dalam kurva distribusi t sebagai berikut :

\section{Gambar 1}

Daerah Penerimaan dan Penolakan $\mathrm{H}_{0}$ (t-test uji $\left.\beta 1\right)$

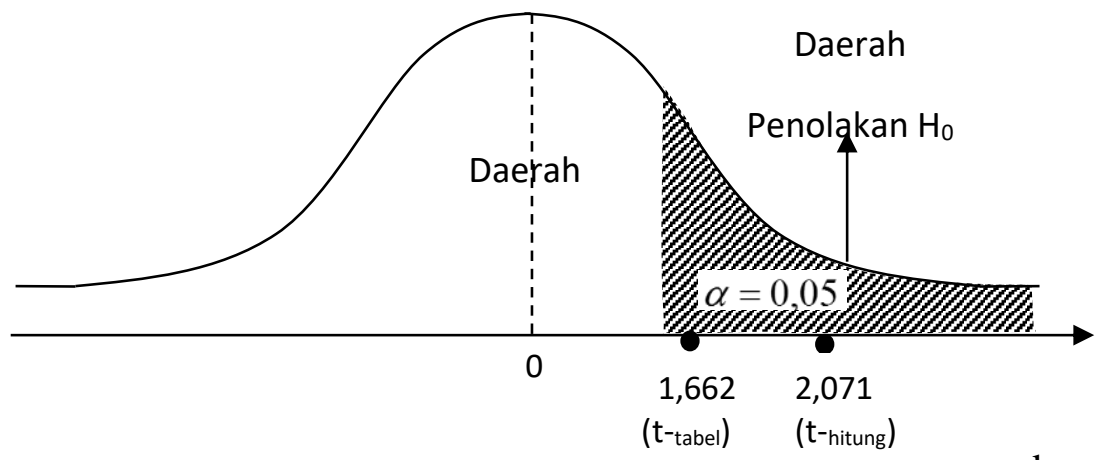

2. Pengaruh promosi terhadap pembelian sepeda motor Yamaha N-Max pada CV. Waja Motor Cab. Ubud Gianyar :

a. Perumusan hipotesis

$\mathrm{H}_{0}: \beta \mathrm{i}=0$ berarti tidak ada pengaruh yang signifikan antara kualitas produk (X1), promosi (X2) dan desain (X3) terhadap pembelian sepeda motor Yamaha N-Max (Y) pada CV. Waja Motor Cabang Ubud Gianyar.

Hi : $\beta \mathbf{i}>0$ berarti ada pengaruh yang signifikan secara parsial antara kualitas produk (X1), promosi (X2) dan desain (X3) terhadap pembelian sepeda motor Yamaha N-Max (Y) pada CV. Waja Motor Cabang Ubud Gianyar.

Sesuai dengan hipotesis alternative ( $\mathrm{Hi}$ ) yang diajukan di atas, maka dalam pengujian ini digunakan uji sisi kanan dengan $\alpha=0,05$ dan $\mathrm{df}=\mathrm{n}-\mathrm{k}-$ 1 .

b. Membandingkan nilai thitung dengan nilai t-tabel, dengan kriteria sebagai berikut :

1) Jika t-hitung $\leq \mathrm{t}$-tabel, maka $\mathrm{H}_{0}$ diterima dan $\mathrm{Hi}$ ditolak.

2) Jika t-hitung $>$ t-tabel, maka $\mathrm{H}_{0}$ ditolak dan $\mathrm{Hi}$ diterima.

c. Perhitungan t-hitung

Dari tabel di atas dapat dilihat bahwa $\mathrm{t}$ hitung dari variabel promosi diperoleh t-hitung $=$ $3,475>$ t-tabel 1,662 dengan 
tingkat signifikansi sebesar 0,001 . Data diatas menunjukan bahwa nilai signifikan yang dihasilkan variabel promosi berada dibawah 0,05 sehingga hipotesis yang menyatakan bahwa promosi memberikan pengaruh yang signifikan terhadap pembelian sepeda motor Yamaha N-Max pada CV.
Waja Motor Cab. Ubud Gianyar secara parsial dapat diterima.

d. Menggambarkan daerah penerimaan dan penolakan hipotesis. Untuk mengetahui bahwa $\mathrm{H}_{0}$ diterima atau ditolak, maka digambarkan dalam kurva distribusi $\mathrm{t}$ sebagai berikut:

\section{Gambar 2}

Daerah Penerimaan dan Penolakan $\mathrm{H}_{0}$ (t-test uji $\beta 2$ )

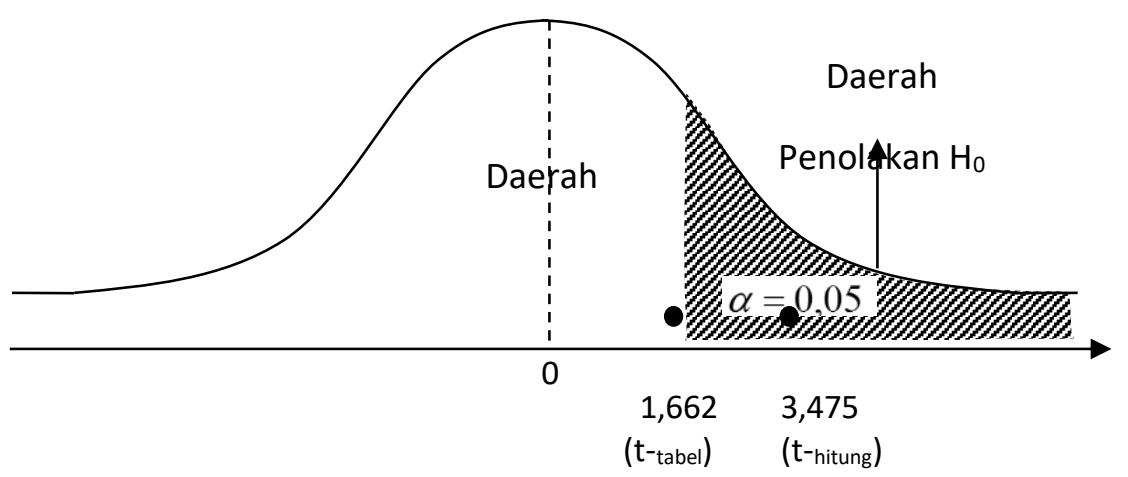

3. Pengaruh desain terhadap pembelian sepeda motor Yamaha N-Max pada CV. Waja Motor Cab. Ubud Gianyar :

a. Perumusan hipotesis

$\mathrm{H}_{0}: \beta \mathrm{i}=0$ berarti tidak ada pengaruh yang signifikan antara kualitas produk (X1), promosi (X2) dan desain (X3) terhadap pembelian sepeda motor Yamaha N-Max (Y) pada CV. Waja Motor Cabang Ubud Gianyar.

Hi : $\beta \mathrm{i}>0$ berarti ada pengaruh yang signifikan secara parsial antara kualitas produk (X1), promosi (X2) dan desain (X3) terhadap pembelian sepeda motor Yamaha NMax (Y) pada CV. Waja Motor Cabang Ubud Gianyar.

Sesuai dengan hipotesis alternative ( $\mathrm{Hi}$ ) yang diajukan di atas, maka dalam pengujian ini digunakan uji sisi kanan dengan $\mathrm{a}=0,05$ dan $\mathrm{df}=\mathrm{n}-\mathrm{k}-$ 1.

b. Membandingkan nilai t-hitung dengan nilai t-tabel, dengan kriteria sebagai berikut :

1) Jika t-hitung $\leq$ t-tabel, maka $\mathrm{H}_{0}$ diterima dan $\mathrm{Hi}$ ditolak. 
2) Jika t-hitung > t-tabel, maka $\mathrm{H}_{0}$ ditolak dan $\mathrm{Hi}$ diterima.

c. Perhitungan t-hitung Dari tabel di atas dapat dilihat bahwa $\mathrm{t}$ hitung dari variabel desain diperoleh t-hitung $=1,786$ $>$ t-tabel 1,662 dengan tingkat signifikansi sebesar 0,077. Data diatas menunjukan bahwa nilai signifikan yang dihasilkan variabel desain berada dibawah 0,05 sehingga hipotesis yang menyatakan bahwa desain memberikan pengaruh yang signifikan terhadap pembelian sepeda motor Yamaha N-Max pada CV. Waja Motor Cab. Ubud Gianyar secara parsial dapat diterima.

d. Menggambarkan daerah penerimaan dan penolakan hipotesis. Untuk mengetahui bahwa $\mathrm{H}_{0}$ diterima atau ditolak, maka digambarkan dalam kurva distribusi t sebagai berikut :

\section{Gambar 3}

Daerah Penerimaan dan Penolakan $\mathrm{H}_{0}$ (t-test uji $\beta 3$ )

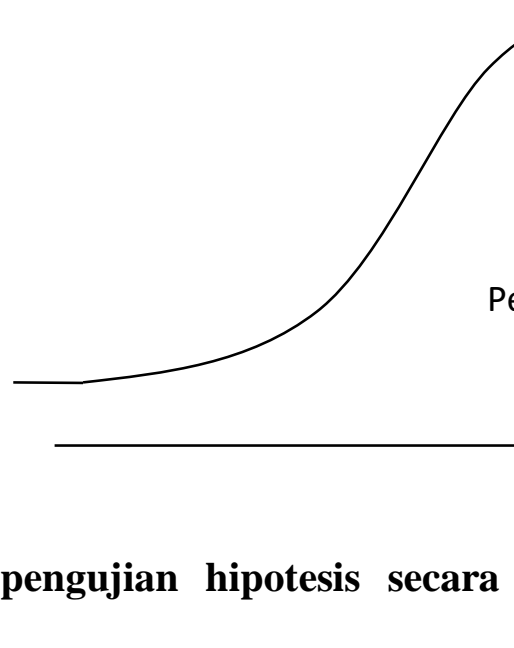

Untuk pengujian pengaruh variabel bebas secara bersama-sama terhadap variabel terikatnya dilakukan dengan menggunakan uji $F$. hasil perhitingan SPSS menunjukkan nilai Fhitung $=10,514>$ F-tabel 2,705 tingkat signifikansi yang dihasilkan adalah sebesar 0.000 yang lebih kecil dari pada 0,05, sehingga bisa dijelaskan bahwa $\mathrm{H} 0$ ditolak, Hi diterima. Artinya hipotesis Hi yang menyatakan bahwa kualitas produk, promosi, dan desain memberikan pengaruh signifikan

\section{KESIMPULAN}

Dari data primer yang diperoleh dari penyebaran kuesioner maka dilakukan pengujian untuk mengetahui jawaban responden. Berdasarkan dari hasil analisis dan pembahasan yang telah diuraika, kualitas produk, promosi, dan desain mempunyai pengaruh yang 
positif dan signifikan secara simultan terhadap keputusan pembelian. Kontribusi variabel tersebut bisa diketahui dari R Square yang diperoleh dengan hasil sebesar 25,7\%. Berarti kualitas produk, promosi, dan desain berpengaruh terhadap keputusan pembelian sebesar 25,7\%, Dalam hal ini variabel promosi berpangaruh lebih kuat karena promosi mempunyai nilai koefisien regresi yang lebih tinggi dengan nilai sebesar 3,475 dibandingkan variabel yang lain. Hal ini menunjukkan promosi memiliki peran yang sangat kuat yang paling berpengaruh untuk meningkatkan pembelian pada CV. Waja Motor Cabang Ubud Gianyar.

\section{SARAN}

Diharapkan bagi perusahaan untuk memperhatikan dan meningkatkan kualitas produk yang lebih baik dengan melakukan inovasi terus menerus serta memenuhi keinginan konsumen yang selalu berubah. Untuk meningkatkan keputusan pembelian, disarankan kegiatan promosi yang berupa pemberian diskon, pemberian hadiah langsung dan garansi harus tetap dilakukan terus agar minat konsumen semakin tinggi dan tertarik untuk membeli, perusahaan harus mampu selalu berinovasi menciptakan desain yang inovatif terutama model warna dan striping. Perusahaan harus lebih memperhatikan keluhan-keluhan pelanggan dan senantiasa memberikan pelayanan yang terbaik bagi konsumen.

\section{DAFTAR PUSTAKA}

Arief 2007, Pemasaran Jasa dan Kualitas Pelayanan, Malang: Bayu Media.

Artika Romal Amrullah, Sasi Agustin. 2016. Pengaruh Kualitas Produk, Harga, Dan Citra Merek Terhadap Keputusan Pembelian Honda Beat" Junal Ilmu Dan Riset Manajemen Vol 5 No. 7. STIESIA. Surabaya.

Assauri, Sofyan. 2002. Manajemen Pemasaran (dalam konsep dan strategi), Jakarta: Rajawali Grafindo.

Basu Swastha, Hani Handoko. 2011. Manajemen Pemasaran Analisis Perilaku Konsumen. Yogyakarta : BPFE.

Fandy Tjiptono. (2008). Strategi Pemasaran: Edisi 3. Yogyakarta : Andi Offset.

Hurriyati, Ratih 2008. Bauran Pemasaran dan Loyalitas Konsumen. Bandung : Alfabeta

Husein Umar, 2003, Metode Penelitian Untuk Skripsi dan Tesis Bisnis,Jakarta : PT. Gramedia Pustaka.

J. Setiadi, Nugroho, SE., MM., 2003, "Perilaku Konsumen Konsep dan Implikasi untuk Strategi dan Penelitian Pemasaran". Jakarta: Kencana.

Kasmir, Pemasaran Bank, Jakarta : Prenada Media,2004 
Kotler, Philip, Manajemen Pemasaran, PT. Prenhallindo, Jakarta 2000

Kotler, Philip.2003. Manajemen Pemasaran. edisi kesebelas, Jakarta: Indeks kelompok Gramedia.

Kotler, Philip. 2005. Manajemen Pemasaran, Jilid 1 dan 2. Jakarta: PT. Indeks Kelompok Gramedia. .(2001). Prinsip-prinsip

Pemasaran (Principles of Marketing), Edisi Bahasa Indonesia, Jilid I. Jakarta: Penerbit Erlangga.

Kotler, Philip dan Armstrong, Gary. (2011). 10 ${ }^{\text {th }}$ Edition. "Marketing an Introduction". Indonesia: Perason.

Nur Achidah, M Mukery Warso Dan Leonardo Budi Hasiolan. 2016. “ Pengaruh Promosi, Harga, dan Desain Terhadap Keputusan Pembelian Sepeda Motor Mio GT (Study Empiris Pada Produk Yamaha Mio GT Di WeleriKendal)

Rambat Lupiyoadi, A.Hamdani, Manajemen Pemasaran Jasa, Jakarta: Salemba Empat.2006
Sangadji, Etta Mamang,Dr.\& Sopiah, Dr. 2013. Perilaku Konsumen. Yogyakarta. ANDI.

Sudoryono. 2016. Manajemen Pemasaran Teori \& Implementasi. Yogyakarta. Andi Offset.

Sugiyono. 2007. Metode Penelitian Kuantitatif Kualitatif dan $R \& D$. Bandung: Alfabeta. . 2013. Metode Penelitian Pendidikan Pendekatan Kuantitatif, Kualitatif, dan $R \& D$. Bandung: Alfabeta. . 2012. Metode Penelitian Bisnis. Bandung : Alfabeta.

Tjiptono, Fandy, 2008, Strategi Pemasaran, Edisi 3, ANDI: Yogyakarta.

Tjiptono, Fandy dan Gregorius Chandra, 2012, Pemasaran Strategik. Yogyakarta, ANDI.

Ummu Habibah, Sumiati. 2016. Pengaruh Kualitas Produk Dan Harga Terhadap Keputusan Pembelian Produk Kosmetik Wardah Di Kota Bangkalan Madura" Jurnal Ekonomi \& Bisnis Vol 1 No. 1. Hal 31-48. FE. Surabaya. 